\title{
Size Effects of the Crystallite of ZSM-5 Zeolites on the Direct Catalytic Conversion of L-Lactic Acid to L, L-Lactide
}

\author{
Qintong Huang, Rui Li, Guangying Fu and Jiuxing Jiang *(B)
}

MOE Key Laboratory of Bioinorganic and Synthetic Chemistry, School of Chemistry, Sun Yat-sen University, Guangzhou 510275, China; huangqt9@mail2.sysu.edu.cn (Q.H.); lirui99@mail2.sysu.edu.cn (R.L.); fugy3@mail.sysu.edu.cn (G.F.)

* Correspondence: jiangjiux@mail.sysu.edu.cn; Tel.: +86-20-84111355

Received: 16 July 2020; Accepted: 31 August 2020; Published: 3 September 2020

\begin{abstract}
ZSM-5 zeolites are commonly used as a heterogeneous catalyst for reactions. Four ZSM-5 catalysts (with various crystallite sizes and a similar ratio of $\mathrm{Si} / \mathrm{Al}$ ) and their ball-milling/surfacepoisoning derivates were used to convert L-lactic acid to L, L-lactide. The reaction products were analyzed by three independent analytical methods (i.e., Proton nuclear magnetic resonance $\left({ }^{1} \mathrm{H} \mathrm{NMR}\right)$, high-pressure liquid chromatography (HPLC), and chiral gas chromatography (GC)) for determining the L, L-lactide yield and L-lactic acid conversion. A clear size effect, i.e., smaller catalysts providing better performance, was observed. Further ball-milling/surface-poisoning experiments suggested that the size effect of the ZSM- 5 catalysts originated from the diffusion-controlled nature of the reaction under the investigated conditions.
\end{abstract}

Keywords: ZSM-5 zeolites; L,L-lactide; size effect; diffusion control

\section{Introduction}

Polylactic acid (PLA), produced by the condensation of lactic acid, is widely used in disposable packaging and in vivo biomedical applications [1], among other applications, due to its biodegradability and biocompatibility. Furthermore, its building block, i.e., lactic acid, is a sustainable and renewable biomass-derived platform molecule that is independent of fossil resources.

To avoid the high reaction temperature required for water removal during the condensation process, industrially manufactured PLA is synthesized via the lactide route. The lactide route enables the production of high-quality, monodispersed, higher molecular weight PLA [2]. Hence, pure optical lactides (i.e., L, L-lactide and/or D, D-lactide) are important intermediates for producing high-quality PLA.

Bellis et al. [3] proposed vapor-phase synthesis over a plug flow reactor. Chang and coworkers [4,5] realized a $94 \%$ yield with almost $100 \%$ enantio-selectivity using a $\mathrm{SnO}_{2}-\mathrm{SiO}_{2}$ nanocomposite catalyst. However, a high yield was only achieved at a relatively low velocity of 1 or $3 \mathrm{~h}^{-1}$. Sels and co-workers proposed a liquid-phase lactide synthesis process [6]. In their work, zeolite was used as a shape-selective catalyst to produce highly optical pure L-lactide (Scheme 1). The acidic form of beta zeolite was proposed as the best catalyst to achieve an $83 \%$ pass yield and a $98 \%$ optical purity. However, the work only compared some zeolites and left crystallite size unexplored.

In this work, a size effect and better performance was observed for ZSM-5 in comparison to beta zeolite. Further ball-milling and surface-poisoning experiments were performed to elucidate the size effect. 


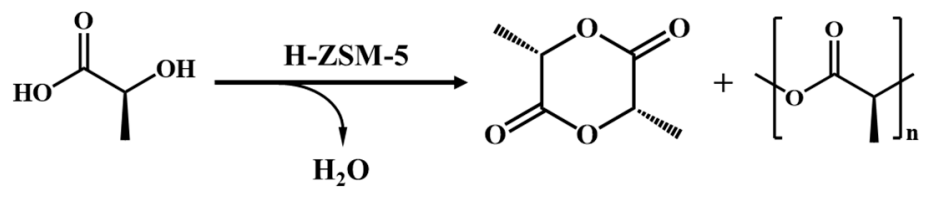

Scheme 1. The current and proposed chemical process for making L, L-lactide and lactyl oligomers from L-lactic acid.

\section{Materials and Methods}

\subsection{Materials}

All chemicals were purchased from Aladdin Chemical Co. (Shanghai, China) and Sigma-Aldrich (St. Louis, MO, USA) and used directly after receiving. Commercial nanocrystalline zeolites of $\mathrm{NH}_{4}-\mathrm{ZSM}-5-\mathrm{I}(\mathrm{CBV} 3020, \mathrm{Si} / \mathrm{Al}=15)$ and $\mathrm{NH}_{4}-\mathrm{ZSM}-5-\mathrm{II}(\mathrm{CBV} 3024 \mathrm{E}, \mathrm{Si} / \mathrm{Al}=15)$ were purchased from Zeolyst (Farmsum, The Netherlands). Micrometer-sized ZSM-5-III (Si/Al = 12) and ZSM-5-IV $(\mathrm{Si} / \mathrm{Al}=10)$ were provided by Wuhan Zhizhen Zeolite Co. (Wuhan, China). ZSM-5-III-b.m. and ZSM-5-IV-b.m. were obtained by ball milling ZSM-5-III $(\mathrm{Si} / \mathrm{Al}=12)$ and ZSM-5-IV $(\mathrm{Si} / \mathrm{Al}=10)$ for half an hour at $60 \mathrm{~Hz}$.

All of the ZSM-5 zeolites were calcined before use for $6 \mathrm{~h}$ at $550{ }^{\circ} \mathrm{C}$, reaching a rate of $2{ }^{\circ} \mathrm{C} / \mathrm{min}$ under a smooth flow of air to obtain the acidic form of ZSM-5 as a catalyst for the transformation of L-lactic acid into L, L-lactide. We named the six acidic forms of the ZSM-5 zeolite ZSM-5-I (I), ZSM-5-II (II), ZSM-5-III (III), ZSM-5-I (IV), ZSM-5-III-b.m. (III-b.m.), and ZSM-5-IV-b.m. (IV-b.m.). When ZSM-5-IV $(\mathrm{Si} / \mathrm{Al}=10)$ was ball milled for $15 \mathrm{~min}$ at $60 \mathrm{~Hz}$, the obtained sample was ZSM-5-IV-b.m.15 min (IV-b.m.-15 min).

\subsection{Methodology}

\subsubsection{Characterization of the ZSM-5 Zeolites}

The X-ray diffraction (XRD) patterns of the ZSM- 5 zeolites were obtained using a Rigaku SmartLab diffractometer (Rigaku Co., Tokyo, Japan) with $\mathrm{Cu} \mathrm{K} \alpha$ monochromatic radiation $(\lambda=0.154178 \mathrm{~nm})$ at $40 \mathrm{kV}$ and $30 \mathrm{~mA}$. The crystallite morphology and size of these ZSM-5 catalysts were investigated by ultra-high-resolution scanning electron microscopy (SEM; FE-SEM SU8010, HITACHI, Tokyo, Japan) and transmission electron microscopy (TEM; JEM-1400 Plus, JEOL, Tokyo, Japan). The Si/Al ratios of the ZSM-5 catalysts were determined by inductively coupled plasma optical emission spectrometry (ICP-OES, Perkin ElmerOptima8300, PerkinElmer, Waltham, MA, USA). The $\mathrm{N}_{2}$ adsorption isotherms of these ZSM- 5 catalysts at $77 \mathrm{~K}$ were measured using a Micrometrics ASAP 2020 Plus (Micrometrics, Norcross, GA, USA) instrument. To investigate the acidic properties of the ZSM-5 catalysts, temperature-programmed desorption of ammonia $\left(\mathrm{NH}_{3}-\mathrm{TPD}\right)$ and pyridine adsorption Fourier-transform infrared spectroscopy spectra (py-IR) were used. The $\mathrm{NH}_{3}$-TPD measurement was conducted using an MFTP-3060 (Xiamen Better Work Intelligent Technology Co., Xiamen, China) instrument with a thermal conductivity detector (TCD), while the py-IR spectra were recorded using a ThermoFisher Scientific RS20 (Thermo Fisher Scientific, Waltham, MA,USA) instrument in situ.

\subsubsection{Synthesis of L, L-Lactide}

First, $0.83 \mathrm{~g}$ of L-lactic acid $(9.21 \mathrm{mmol}, 98 \%)$ dissolved in $0.83 \mathrm{~g}$ of water was placed into a $25 \mathrm{~mL}$ round-bottom flask, which was equipped with a magnetic stirrer and a Dean-Stark apparatus. Subsequently, $10 \mathrm{~mL}$ of $o$-xylene/p-xylene (99\%) was added, as well as $0.2 \mathrm{~g}$ of calcined zeolite. Then, the mixture was heated at the reflux temperature of $o$-xylene $\left(144^{\circ} \mathrm{C}\right)$ for $4 \mathrm{~h}$. After the reaction, the mixture was homogenized by the addition of $10 \mathrm{~mL}$ of acetonitrile $(99 \%)$. The zeolite was removed by centrifugation. 
The condition of the surface-poisoning experiment was the same as the above; only $0.031 \mathrm{~g}$ of 2,4-dimethylquinoline was added to poison the surface of Sample II to eliminate the influence of the surface reaction on the catalytic results.

\subsubsection{Analytical Methods}

${ }^{1} \mathrm{H}$ NMR analysis of the production: After accurately measuring the total mass of the homogeneous reaction mixture, a $1 \mathrm{~mL}$ sample was taken from the homogeneous reaction mixture, weighed, and then dried in a gentle flowing nitrogen atmosphere to remove the $o$-xylene and acetonitrile solvents. Mild drying in a nitrogen atmosphere can remove the solvent without affecting the less-volatile lactide and lactic acid mixtures. The dry sample was dissolved in $0.5 \mathrm{~mL}$ of DMSO- $\mathrm{d}_{6}$, transferred to NMR tubes, and then measured on a Bruker Avance $400 \mathrm{MHz}$ NMR (Bruker Co., Billerica, MA, USA) spectrometer with an automated sampler.

Chiral GC analysis: GC analysis was performed on an Agilent 7890B system (Agilent Technologies, Santa Clara, CA, USA) with a chiral capillary column, equipped with a flame ionization detector (FID) maintained at $275^{\circ} \mathrm{C}$ and Agilent MassHunter Qualitative Analysis software. The injection port temperature was $225^{\circ} \mathrm{C}$, and the initial column temperature was set at $70^{\circ} \mathrm{C}$. This temperature was maintained for $5 \mathrm{~min}$ before being increased to $150^{\circ} \mathrm{C}$ at $15^{\circ} \mathrm{C} / \mathrm{min}$, after which the oven was ramped up to $180^{\circ} \mathrm{C}$ at $25^{\circ} \mathrm{C} / \mathrm{min}$ and held there for $24 \mathrm{~min}$.

HPLC analysis: A $1 \mathrm{~mL}$ sample was taken, weighed, and then dried under a flowing nitrogen atmosphere. This dry sample was dissolved in $1 \mathrm{~mL}$ of ultra-pure water and analyzed using reverse phase-HPLC on an Agilent 1100 Series Products Spectra System (Agilent Technologies, Santa Clara, CA, USA) equipped with a PL Hi-Plex H Guard $50 \times 7.7 \mathrm{~mm}$ column, a PL Hi-Plex H $300 \times 7.7 \mathrm{~mm}$ column, and a 1260 Infinity UV-Vis detector at $210 \mathrm{~nm}$. Lastly, $0.001 \mathrm{M} \mathrm{H}_{2} \mathrm{SO}_{4}$ solvent was used as a mobile phase, and the flow rate was $0.6 \mathrm{~mL} / \mathrm{min}$.

\section{Results and Discussion}

\subsection{Characterization of the ZSM-5 Zeolites with Different Crystallite Sizes}

The XRD patterns of the six ZSM-5 zeolites are shown in Figure 1. Characteristic diffraction peaks $\left(2 \theta=7.8^{\circ}, 8.7^{\circ}, 23.1^{\circ}, 23.8^{\circ}\right.$, and $\left.24.3^{\circ}\right)$ [7] for the ZSM-5 structure (MFI) were found in all the catalysts, and no impurity peaks were surveyed. Across Samples I-IV, the XRD patterns show very sharp reflections and low background signal, indicating their superior crystalline properties. The relative crystallinity of the ZSM-5 zeolites with different crystallite sizes was determined from the peak area between $2 \theta=22-25^{\circ}$ using Sample I as the standard [7,8], and the results are listed in Table 1 . The texture properties of the ZSM- 5 zeolites were characterized by nitrogen adsorption/desorption and ICP-OES analysis (Table 1). Examination of the data shows that the Brunauer-Emmett-Teller (BET) surface area and the t-plot micropore volumes of Samples I-IV are similar, but the external surface area increases as the crystallite size decreases. Different shapes and sizes of the catalysts can be observed in the SEM micrographs (Figure $2 a, d, g, j$ ) and the TEM images (Figure $2 b, e, h, k$ ). Samples I and II are round cuboids, but Samples III and IV are sharp rectangular blocks. All of the ZSM-5 catalysts were agglomerated by microcrystals to form secondary particles. The distribution of the crystallite sizes was obtained from 300 randomly selected microcrystalline samples. Sample I shows the smallest crystallite size $(0.05-0.20 \mu \mathrm{m}$ in length and $\sim 0.08 \mu \mathrm{m}$ in width), while Sample II $(0.08-0.30 \mu \mathrm{m}$ in length and $\sim 0.1 \mu \mathrm{m}$ in width) shows a larger crystallite size than Sample I. Sample III displays a length of $0.75-3 \mu \mathrm{m}$ and a width of $0.5 \mu \mathrm{m}$, although Sample IV exhibits the largest crystallite size (a length of $1-4 \mu \mathrm{m}$ and a width of $1 \mu \mathrm{m})$. 


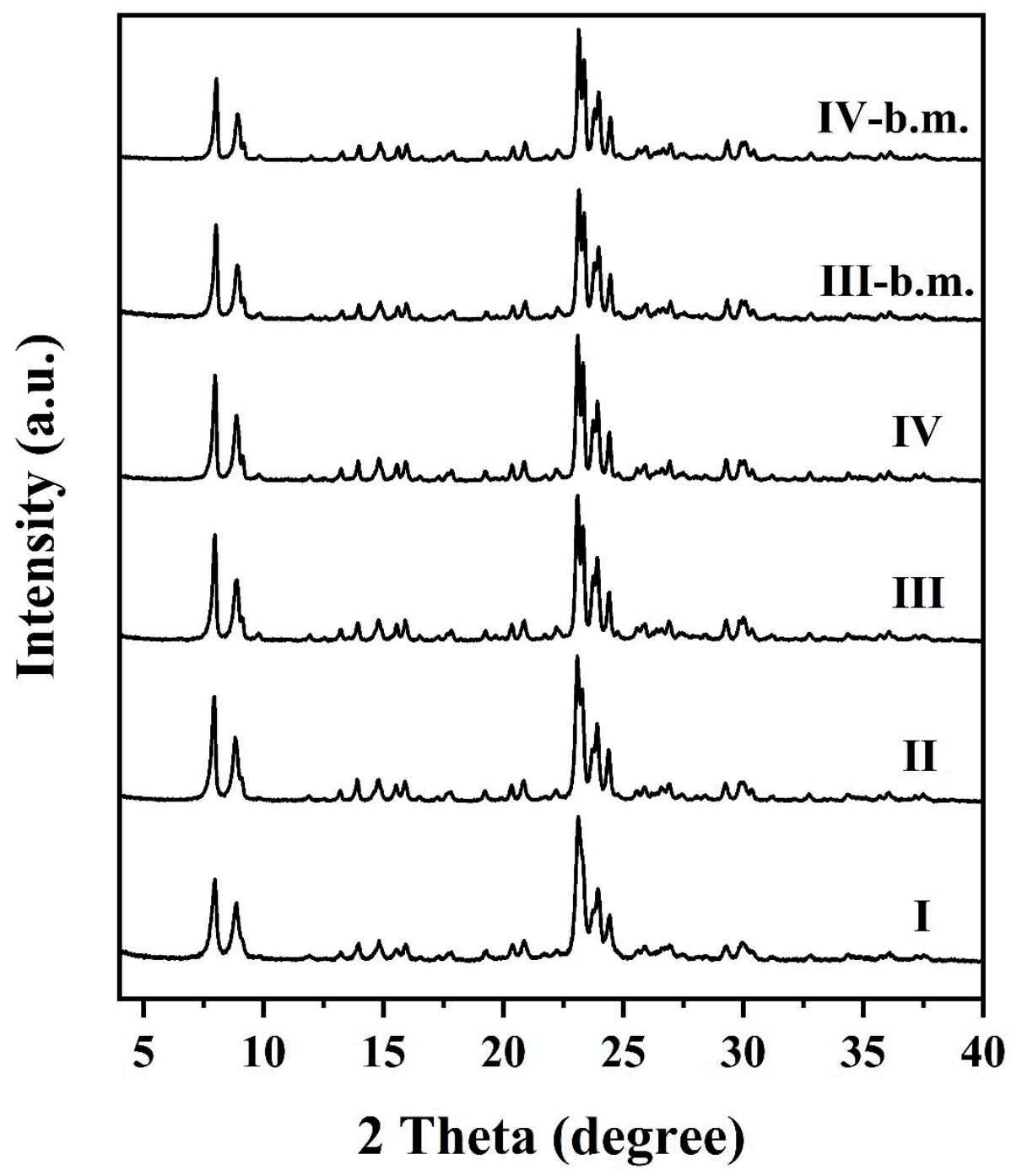

Figure 1. The X-ray diffraction patterns of ZSM-5 zeolites I-IV, III-b.m., and IV-b.m.

Table 1. Structural and textural properties of ZSM-5 zeolites I-V, III-b.m., and IV-b.m.

\begin{tabular}{|c|c|c|c|c|c|}
\hline Zeolite & $\begin{array}{c}\text { Relative } \\
\text { Crystallinity (\%) }\end{array}$ & $\begin{array}{l}\text { Si/Al Molar } \\
\text { Ratios }^{1}\end{array}$ & $\begin{array}{l}\mathrm{A}_{\mathrm{BET}}{ }^{2} \\
\left(\mathrm{~m}^{2} / \mathrm{g}\right)\end{array}$ & $\begin{array}{l}V_{\text {micro }}{ }^{3} \\
\left(\mathrm{~cm}^{3} / \mathrm{g}\right)\end{array}$ & $\begin{array}{c}\text { External Surface } \\
\text { Area }^{3}\left(\mathrm{~m}^{2} / \mathrm{g}\right)\end{array}$ \\
\hline I & 100.0 & 12.4 & 397.5 & 0.15 & 42.6 \\
\hline II & 90.0 & 12.0 & 393.4 & 0.15 & 36.7 \\
\hline III & 89.1 & 10.7 & 411.8 & 0.16 & 12.0 \\
\hline IV & 80.0 & 9.3 & 403.7 & 0.16 & 6.7 \\
\hline III-b.m. & 81.4 & 10.6 & 362.9 & 0.14 & 27.3 \\
\hline IV-b.m. & 70.6 & 9.5 & 336.2 & 0.13 & 25.1 \\
\hline
\end{tabular}

${ }^{1}$ Measures by ICP-OES; ${ }^{2}$ Brunauer-Emmett-Teller (BET) surface area; ${ }^{3}$ micropore volume and external surface area determined by t-plot.

When Samples III and IV were milled, we gained III-b.m. (0.1-0.8 $\mu \mathrm{m}$ in length and $\sim 0.2 \mu \mathrm{m}$ in width) and IV-b.m. (0.2-0.8 $\mu \mathrm{m}$ in length and $\sim 0.3 \mu \mathrm{m}$ in width), which were irregular pieces (Figure $2 \mathrm{~m}, \mathrm{n}, \mathrm{p}, \mathrm{q}$ ). In Figure 1, for III-b.m. and IV-b.m., the broad XRD peaks around $25^{\circ}$ imply the presence of amorphous material impurity because of the ball milling. Meanwhile, the BET surface area and the t-plot micropore volume of III-b.m. and IV-b.m. decreased marginally, but the external surface area increased (Table 1). 

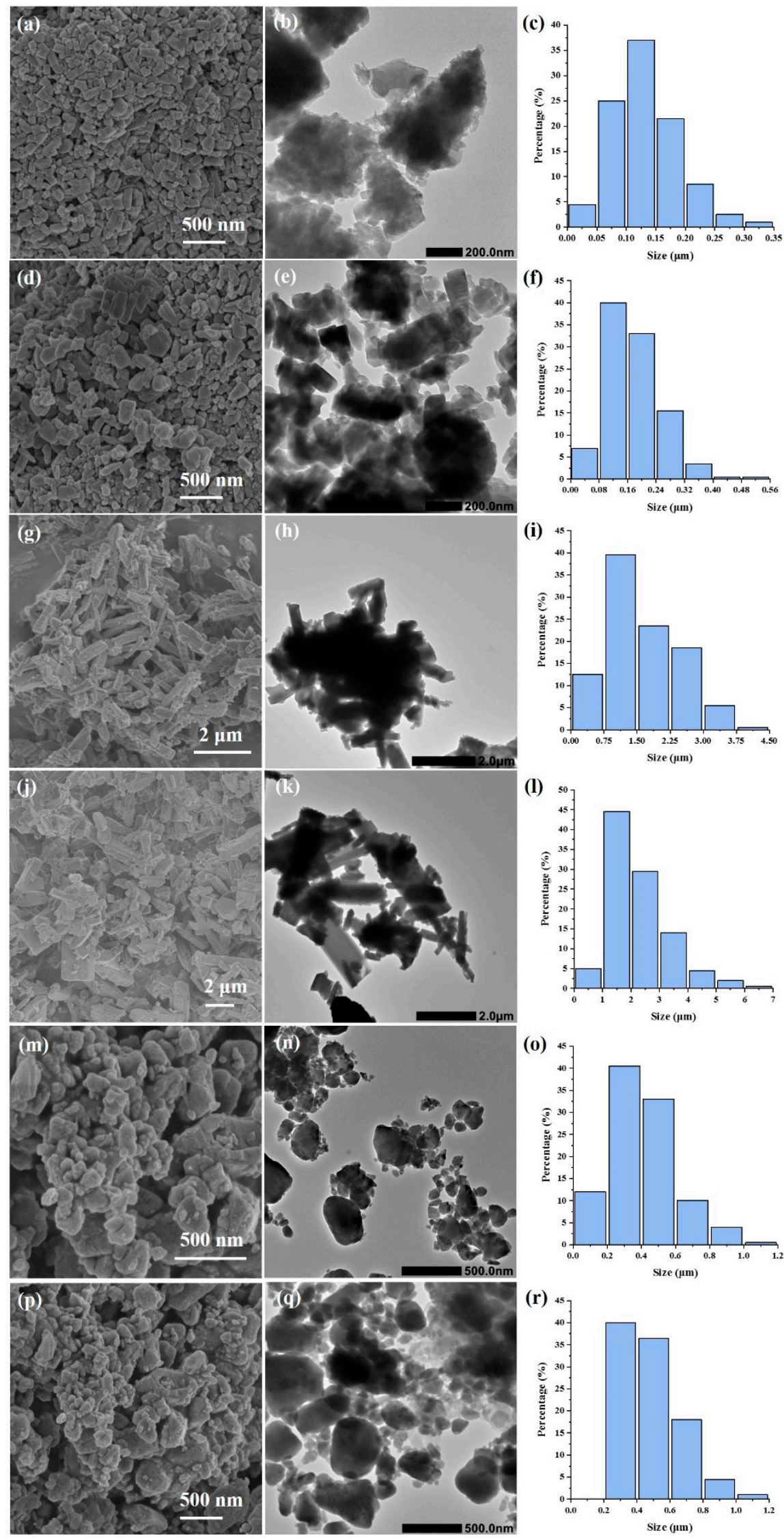

Figure 2. The scanning electron microscopy (SEM) micrographs, transmission electron microscopy (TEM) images, and distribution curves of the crystallite sizes of the ZSM-5 zeolites: (a-c) I; (d-f) II; (g-i) III; (j-1) IV; (m-o) III-b.m.; (p-r) IV-b.m. 
The acid strength and the number of the acidic sites on the surfaces of the six kinds of ZSM-5 zeolites were determined by $\mathrm{NH}_{3}$-TPD measurement (as shown in Figure 3a). All of the ZSM- 5 catalysts demonstrated two similar $\mathrm{NH}_{3}$ desorption peaks-a low-temperature peak at approximately $195^{\circ} \mathrm{C}$ and a high-temperature peak at about $405^{\circ} \mathrm{C}$, generally belonging to the $\mathrm{NH}_{3}$ chemisorbed on weak and strong acidic sites [9-13], respectively. The strength of the acid sites and the number of weak and strong acid sites of these six ZSM- 5 samples are basically the same due to the similar Si/Al molar ratio. The py-IR spectra were used to detect the Lewis and Brønsted sites of the ZSM- 5 catalysts, and Figure $3 \mathrm{~b}$ exhibits the py-IR spectra of these acquired ZSM-5 zeolites in the region of $1400-1700 \mathrm{~cm}^{-1}$. The band in the $1450 \mathrm{~cm}^{-1}$ region belongs to pyridine adsorbed on the Lewis acid sites, while the band in the $1540 \mathrm{~cm}^{-1}$ region is attributed to pyridine adsorbed on the Brønsted acid sites. [14,15] These results indicate that all of the samples have similar amounts of Lewis and Brønsted acid sites. The data in Table 2 show that ZSM- 5 zeolites with different crystallite sizes exhibit a similar concentration of both Brønsted and Lewis acidic sites at $150^{\circ} \mathrm{C}$. [16] Thus, the influence of the acidic properties on the catalytic reaction is insignificant.
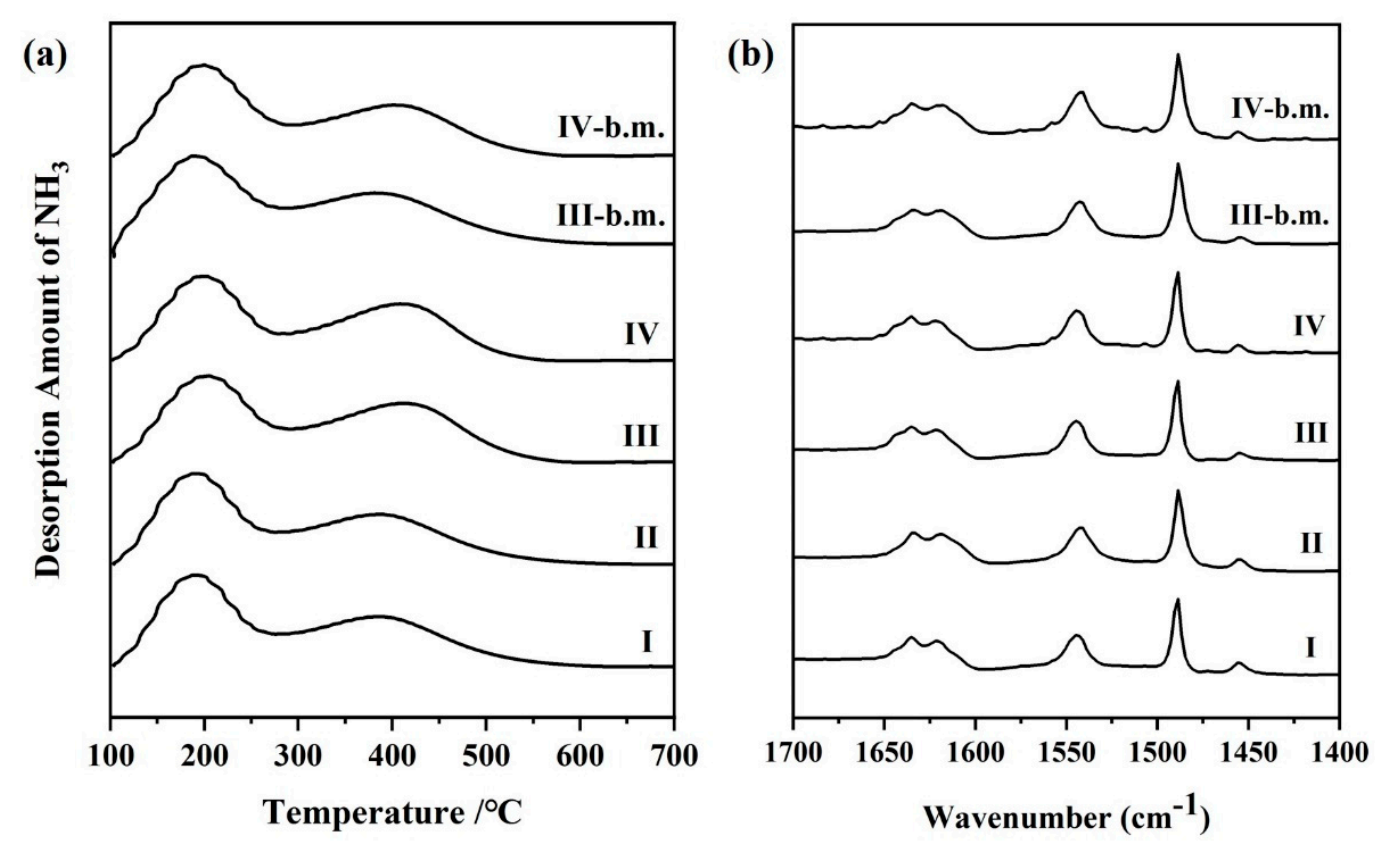

Figure 3. (a) Temperature-programmed desorption of ammonia $\left(\mathrm{NH}_{3}-\mathrm{TPD}\right)$ profiles of various $\mathrm{ZSM}-5$ zeolites; and (b) infrared spectra of adsorbed pyridine on various ZSM-5 zeolites at a desorption temperature of $150{ }^{\circ} \mathrm{C}$.

Table 2. Results for the IR spectra of pyridine adsorbed on the different ZSM-5 zeolites after desorption at $150{ }^{\circ} \mathrm{C}$.

\begin{tabular}{ccccccc}
\hline Catalyst & I & II & III & IV & III-b.m. & IV-b.m. \\
\hline $\mathrm{B}^{1}(\mu \mathrm{mol} / \mathrm{g})$ & 148.2 & 156.5 & 171.1 & 187.1 & 164.5 & 180.2 \\
$\mathrm{~L}^{2}(\mu \mathrm{mol} / \mathrm{g})$ & 48.0 & 45.3 & 40.5 & 39.1 & 43.8 & 45.0 \\
Total acid $(\mathrm{B}+\mathrm{L})(\mu \mathrm{mol} / \mathrm{g})$ & 196.2 & 201.8 & 211.6 & 226.2 & 208.3 & 225.2 \\
\hline
\end{tabular}

${ }^{1}$ B: Brønsted acid sites; ${ }^{2}$ L: Lewis acid sites.

\subsection{Transformation of L-Lactic Acid into L, L-Lactide}

The catalytic performance of various ZSM- 5 zeolites was appraised under the same reaction conditions. In a typical reaction system, the desired amounts of L-lactic acid, water, ZSM-5, and $o$-xylene were mixed in a round-bottom flask, which was then connected to a Dean-Stark apparatus (Figure S1). 
After that, the mixture was applied under continuous water expunction via the reflux of $o$-xylene. The product yield and selectivity of the desired lactide were determined by ${ }^{1} \mathrm{H}$ NMR, HPLC, and chiral GC. The details of a typical ${ }^{1} \mathrm{H}$ NMR spectrum in DMSO- $\mathrm{d}_{6}$ in the methine region is given in Figure S2, revealing the conversion of L-lactic acid to L, L-lactide from four reaction mixtures taken at different times. Analyzing the samples in the methine region allows distinguishing between monomeric L-lactic acid; L, L-lactide; the center lactyl units of linear oligomers; and the - $\mathrm{COOH}$ and $-\mathrm{OH}$ end groups of linear oligomers. [6,17] In general, the L, L-lactide yield; L-lactic acid conversion; and oligomers were measured by ${ }^{1} \mathrm{H}$ NMR integration, relative to the total amount of lactyl-containing products present. HPLC analysis is dependable and allows the admeasurement of L-lactic acid conversion and the yields of all lactyl substances involved. Compared to ${ }^{1} \mathrm{H}$ NMR, which provides the average oligomer length, HPLC analysis can separate all oligomers encountered [18]. This chiral GC enables us to discriminate L, L-lactide; D, D-lactide; and meso-lactide [6]; however, due to the limited volatility of L-lactic acid, GC cannot accurately quantify it. Usually, GC analysis is only used as an auxiliary confirmation tool to confirm the yields of L, L-lactide produced by optimized catalytic reactions and to determine that there is no substantial degree of meso-lactide formation. In this study, there were no other organic species, but condensation products were sought out in the reaction mixtures by HPLC and GC, which corroborated the selectivity of the reaction to the condensation products and the correctness of the ${ }^{1} \mathrm{H}$ NMR analysis. The yields of L, L-lactide obtained by these three independent analytical methods were in good agreement with one another. Figure S3 shows the kinetics of the reaction using Sample I. It can be observed that at the beginning, $2 \%$ of oligomers (mainly dimers and trimers) are present. The maximum value of the oligomers was reached after a short contact time. In the third hour, the catalytic reaction was close to completion.

Figure 4 and Table S1 compares the catalytic performance of the H-form of the ZSM- 5 catalysts with different crystallite sizes in $o$-xylene at $144^{\circ} \mathrm{C}$ for $4 \mathrm{~h}$. The nano-sized I sample shows the highest selectivity for lactide synthesis, yielding nearly $89 \%$ at full L-lactic acid conversion, compared to $9 \%$ at only $20 \%$ conversion in the absence of a catalyst. The L, L-lactide yield, L-lactic acid conversion, and selectivity decreased with the increase in crystallite size.

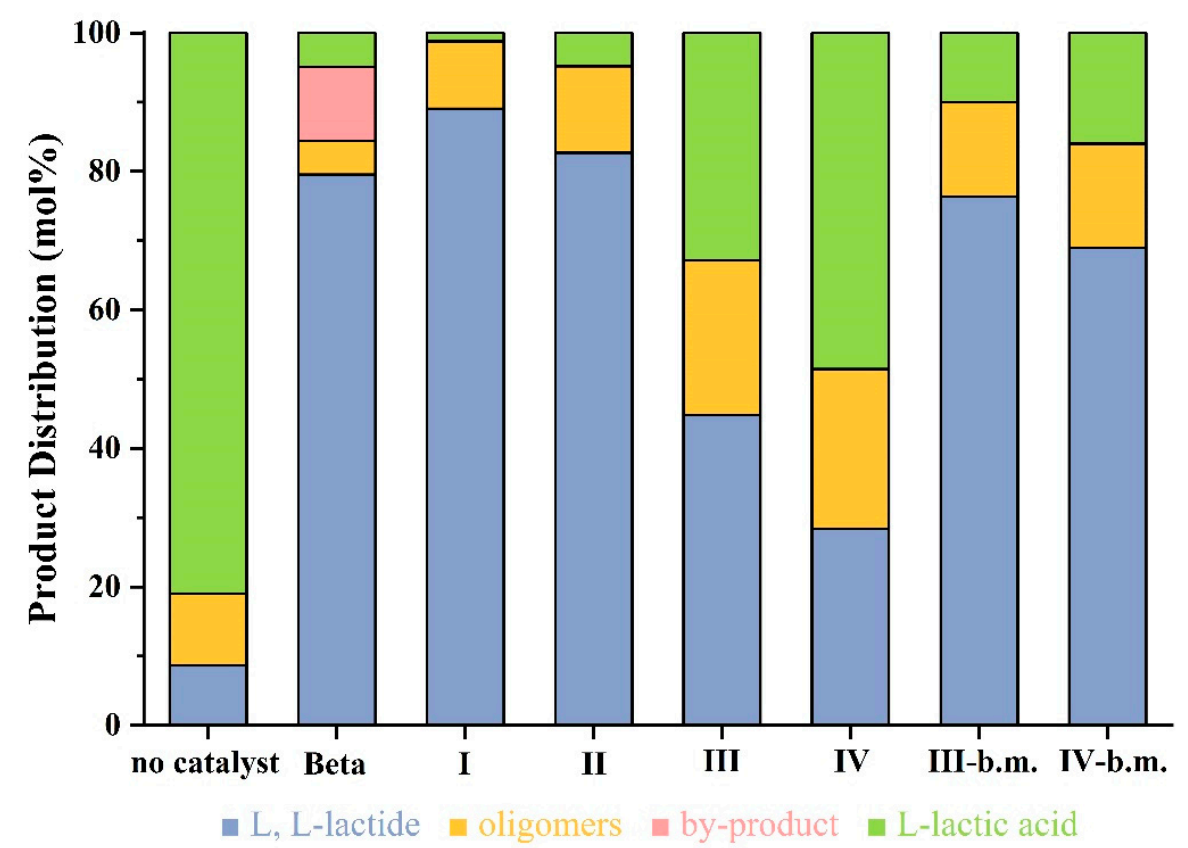

Figure 4. The product distribution of L-lactic acid to L, L-lactide over the ZSM-5 zeolites.

Figure S4 shows the product distributions of the reaction on different solvents with/without surface poisoning. The $p$-xylene provides a subtle difference from $o$-xylene. The surface poisoning 
experiment reveals that external surface acid sites play important roles, and that the internal acid sites also exhibit activity-however, with limited diffusion.

When we ball milled the micron-sized III and IV samples into the nano-sized III-b.m., IV-b.m.-15 min, and IV-b.m. (30 min) samples, the L, L-lactide conversion and selectivity increased significantly. In particular, IV, IV-b.m.-15 min, and IV-b.m. (30 min) continuously improved the catalytic performance (Figure S5). The ball-milled catalysts not only exposed more internal acid sites but also improved the reactant/product mass transfer, which is also consistent with the results of the surface-poisoning experiments. Furthermore, the change in morphology during the ball-milling process, i.e., break down in the longest dimension, may also have contributed to increasing the exposure of the straight 10-ring channel. As a consequence, the catalytic performance improved due to the shorter diffusion path. In general, besides reducing the particle size of the primary catalyst, the effect of the external (liquid-solid) mass transfer resistance can be eliminated by increasing (a) the amount of catalyst and (b) the reaction temperature [19]. However, the amount of catalyst is limited by the net adsorption of the reactant/product by the catalyst, while the reaction temperature is limited by the side reactions. The internal (pore diffusion) mass transfer is determined by the intrinsic pore size and pore volume of ZSM-5. Based on the results of the experiments, both external and internal mass transfer influence the overall effectiveness of the mass transfer. Further work to evaluate the contributions of both internal and external mass transfer is being conducted in our laboratory.

\section{Conclusions}

ZSM-5 catalysts with different crystallite sizes were analyzed by XRD, SEM, $\mathrm{N}_{2}$ adsorption/ desorption, ICP, $\mathrm{NH}_{3}-\mathrm{TPD}$, and pyridine IR. Then, these ZSM-5 catalysts and their derivatives were applied to the reaction of L-lactic acid conversion into L, L-lactide. A clear size effect of the ZSM- 5 catalysts, i.e., smaller crystallites providing better performance, was observed. Further ball-milling and surface-poisoning experiments indicated that this size effect mainly originated from the diffusion-controlled nature of the reaction under the investigated conditions. Therefore, this work highlights that any operations to improve mass transfer-e.g., smaller catalyst particle sizes, a shorter b-axis 2D layer, or a hierarchical structure- during synthesis or post-synthesis could enhance the catalytic performance of the reaction.

Supplementary Materials: The following are available online at http://www.mdpi.com/2073-4352/10/9/781/s1. Characterization procedure for ZSM-5 catalysts' acidity; Figure S1: General lab-scale setup; Figure S2: Reaction progress using Sample I as the catalyst according to ${ }^{1} \mathrm{H}$ NMR in DMSO- $\mathrm{d}_{6}$; Figure S3: Kinetics of the reaction; Table S1: The results of the reaction with the ZSM-5 catalysts; Figure S4. The product distribution of L-lactic acid to L, L-lactide over Sample II in $p$-xylene and the results of poisoning the surface of Sample II with 2,4-dimethylquinoline in $o$-xylene; Figure S5: The SEM images and the distribution curves of the crystallite sizes of Samples IV, IV-b.m.-15 min, and IV-b.m. (30 min), and the product distribution of L-lactic acid to L, L-lactide over Samples IV, IV-b.m.-15 min, and IV-b.m. (30 min).

Author Contributions: Q.H. and J.J. conceived and designed the experiments; Q.H. conducted the experiments; Q.H., R.L., and G.F. performed the characterization and evaluation of the data; Q.H. and J.J. discussed the data and wrote the manuscript. All authors have read and agreed to the published version of the manuscript.

Funding: This research was funded by Natural Science Foundation of China (Grant No. 21971259) and Sinopec.

Conflicts of Interest: The authors declare no conflict of interest.

\section{References}

1. Madhavan Nampoothiri, K.; Nair, N.R.; John, R.P. An overview of the recent developments in polylactide (PLA) research. Bioresour. Technol. 2010, 101, 8493-8501. [CrossRef] [PubMed]

2. Dechy-Cabaret, O.; Martin-Vaca, B.; Bourissou, D. Controlled Ring-Opening Polymerization of Lactide and Glycolide. Chem. Rev. 2004, 104, 6147-6176. [CrossRef] [PubMed]

3. Harold, E.B.; Kamlesh, K.B. Continuous catalyzed vapor phase dimeric cyclic ester process. U.S. Patent 5138074A, 11 August 1992. 
4. Upare, P.P.; Yoon, J.W.; Hwang, D.W.; Lee, U.H.; Hwang, Y.K.; Hong, D.-Y.; Kim, J.C.; Lee, J.H.; Kwak, S.K.; Shin, H.; et al. Design of a heterogeneous catalytic process for the continuous and direct synthesis of lactide from lactic acid. Green Chem. 2016, 18, 5978-5983. [CrossRef]

5. Park, H.W.; Chang, Y.K. Economically Efficient Synthesis of Lactide Using a Solid Catalyst. Org. Process Res Dev. 2017, 21, 1980-1984. [CrossRef]

6. Dusselier, M.; Van Wouwe, P.; Dewaele, A.; Jacobs, P.A.; Sels, B.F. Shape-selective zeolite catalysis for bioplastics production. Science 2015, 349, 78-80. [CrossRef] [PubMed]

7. Gao, Y.; Zheng, B.; Wu, G.; Ma, F.; Liu, C. Effect of the Si/Al ratio on the performance of hierarchical ZSM-5 zeolites for methanol aromatization. RSC Adv. 2016, 6, 83581-83588. [CrossRef]

8. Palcic, A.; Ordomsky, V.V.; Qin, Z.; Georgieva, V.; Valtchev, V. Tuning Zeolite Properties for a Highly Efficient Synthesis of Propylene from Methanol. Chemistry 2018, 24, 13136-13149. [CrossRef] [PubMed]

9. Xia, W.; Chen, K.; Takahashi, A.; Li, X.; Mu, X.; Han, C.; Liu, L.; Nakamura, I.; Fujitani, T. Effects of particle size on catalytic conversion of ethanol to propylene over H-ZSM-5 catalysts-Smaller is better. Catal. Commun. 2016, 73, 27-33. [CrossRef]

10. Jabbari, A.; Abbasi, A.; Zargarnezhad, H.; Riazifar, M. A study on the effect of SiO2/Al2O3 ratio on the structure and performance of nano-sized ZSM-5 in methanol to propylene conversion. React. Kinet. Mech. Catal. 2017, 121, 763-772. [CrossRef]

11. Lónyi, F.; Valyon, J. On the interpretation of the NH3-TPD patterns of H-ZSM-5 and H-mordenite. Microporous Mesoporous Mater. 2001, 47, 293-301. [CrossRef]

12. Bian, C.; Wang, X.; Yu, L.; Zhang, F.; Zhang, J.; Fei, Z.; Qiu, J.; Zhu, L. Generalized Methodology for Inserting Metal Heteroatoms into the Layered Zeolite Precursor RUB-36 by Interlayer Expansion. Crystals 2020, 10, 530. [CrossRef]

13. Ma, F.; Li, H.L.; Jiang, J.X. Furfural Reduction via Hydrogen Transfer from Supercritical Methanol. Chem. Res. Chin. Univ. 2019, 35, 498-503. [CrossRef]

14. Martin, A.; Wolf, U.; Nowak, S.; Lucke, B. Pyridine-i.r. investigations of hydrothermally treated dealuminated HZSM-5 zeolites. Zeolites 1991, 11, 85-87. [CrossRef]

15. Yang, L.; Liu, Z.; Liu, Z.; Peng, W.; Liu, Y.; Liu, C. Correlation between H-ZSM-5 crystal size and catalytic performance in the methanol-to-aromatics reaction. Chin. J. Catal. 2017, 38, 683-690. [CrossRef]

16. Emeis, C.A. Determination of Integrated Molar Extinction Coefficients for Infrare Absorption Bands of Pyridine Adsorbed on Solid Acid Catalysts. J. Catal. 1993, 141, 347-354. [CrossRef]

17. Espartero, J.L.; Rashkov, I.; Li, S.M.; Manolova, N.; Vert, M. NMR Analysis of Low Molecular Weight Poly(lactic acid)s. Macromolecules 1996, 29, 3535-3539. [CrossRef]

18. Vu, D.T.; Kolah, A.K.; Asthana, N.S.; Peereboom, L.; Lira, C.T.; Miller, D.J. Oligomer distribution in concentrated lactic acid solutions. Fluid Phase Equilib. 2005, 236, 125-135. [CrossRef]

19. Ercan, C.; Dautzenberg, F.M.; Yeh, C.Y.; Barner, H.E. Mass-Transfer Effects in Liquid-Phase Alkylation of Benzene with Zeolite Catalysts. Ind. Eng. Chem. Res. 1998, 37, 1724-1728. [CrossRef] 